\title{
How to Optimize Population Screening Programs for Breast Cancer Using Mathematical Models
}

\author{
Montserrat Rue et al. ${ }^{1}$ \\ Research Group on Economic Evaluation and Health, Universities of \\ Lleida and Rovira $i$ Virgili \\ Spain
}

\section{Introduction}

Breast cancer (BC) mortality in Western countries has followed a downward trend since the early 1990s. However, BC remains the most common cancer in women worldwide and the leading cause of premature mortality in women aged 35 to 64 years (Ferlay et al. (2007)).

Despite the widespread use of mammography, there is an intense debate in the scientific community about the benefits and harms of screening for BC (Autier et al. (2011); Duffy et al. (2010); Jorgensen \& Gotzsche (2009); Tabar et al. (2003)). The guidelines of the US Prevention Services Task Force in 2009 recommending biennial screening starting at age 50 (USPSTF (2009)) originated dissension within the scientific community and BC interest groups. At present, the screening recommendations reflect this dissent (ACOG (2011); Schousboe et al. (2011)).

There is a need to consider optimization because, over time, technological improvements allow access to programs that provide better results in exchange for higher costs. In an environment where resources are scarce, policy makers face the possibility of their budget being allocated to different programs, and need information on how to optimally allocate resources. Economic evaluation helps them in decision making. One of the methods used in economic evaluation -efficiency analysis- aims to maximize quality-adjusted life years (QALYs) subject to the constraint of a fixed budget or the amount that society is willing to pay per QALY (Abellán et al. (2008)). The QALYs take account of both the positive effects of each technology as well as the adverse effects.

Evaluating the impact and costs of early detection programs using experimental designs is not feasible. The randomised controlled trials currently have strong limitations, such as sample size, long follow-up times and group contamination. It is difficult to use randomized controlled trials to determine optimal ages and periodicities or to customize screening to different $\mathrm{BC}$ risk groups. Although mathematical models have advantages and drawbacks, they allow to include efficiency principles in the analysis.

Mathematical models can be used to design an optimal strategy for BC screening. Benefits, adverse effects and the costs of screening and treatment over time need to be considered.

\footnotetext{
${ }^{1}$ Misericordia Carles, Ester Vilaprinyo, Roger Pla, Montserrat Martinez-Alonso, Carles Forne, Albert Roso and Arantzazu Arrospide
} 
The aim of this chapter is a) to review the main characteristics and outcomes related to early detection of $\mathrm{BC}$ and $\mathrm{b}$ ) to describe how a mathematical model can help to find an optimal screening strategy.

\section{Important issues related to BC early detection}

\subsection{Measuring the benefits of early detection of $B C$}

In the USA, the National Cancer Institute started an initiative, the Cancer Intervention and Surveillance Modeling Network (CISNET), using modeling to inform and guide clinical decisions and health planning for cancer control. Their landmark study on BC, which measured the impact of mammography and adjuvant therapy on the decline in US BC mortality in the period 1975/2000, showed that each intervention contributed about equally to this decline (Berry et al. (2005); Cronin et al. (2006); Feuer (2006)).

In a study about the effectiveness of early detection on mortality reduction in Catalonia (Spain), we found that relative BC mortality reduction varied from $20 \%$ for biennial exams in the 50 to 69 age interval to 30\% for annual exams in the 40 to 74 age interval (Rue et al. (2009)). When strategies differed in periodicity but not in the age interval of exams, biennial screening achieved almost $80 \%$ of the annual screening mortality reduction.

When assessing the effectiveness of $\mathrm{BC}$ early detection interventions there is currently a debate about the balance of benefits (mortality reduction, in general well established) and adverse effects, much less studied. Nowadays there is an increasing trend to encourage the study of adverse effects of screening (Black (2000); Jorgensen et al. (2007); USPSTF (2009)) and also the way to communicate the risks of screening to health professionals, women, and the general population (Gotzsche et al. (2009)).

\subsection{Adverse effects of screening: false positive and false negative results, interval cancers and overdiagnosis}

The use of mammography as a screening test has adverse effects, which can decrease quality of life and increase costs, morbidity and mortality. An optimal screening program should minimize the frequency of adverse events while maintaining or even increasing benefits. Figure 1 presents a flow chart of a population screening program.

Some of the adverse effects of screening mammograms are:

- False positive (FP) results. These occur when the mammogram is abnormal but no cancer is actually present. Abnormal mammograms are followed up with additional tests, in some cases invasive tests. FP are the consequence of a lack of specificity of mammography. In Spain, Roman et al. (2011a) examined how protocol-related and women's characteristics affect the cumulative risk of FP over 10 sequential mammograms in a retrospective cohort of 1,565,364 women, from 1990 to 2006. The cumulative FP risk for a woman who starts screening at age 50 was $20 \%$, ranging from $7 \%$ to $51 \%$ in the lowest and highest risk profiles, respectively. The cumulative risk for invasive procedures was $1.8 \%$, ranging from $1.6 \%$ to $12 \%$.

Mandelblatt et al. (2009) found that more FP results occur in strategies that initiate screening at age 40 than in those that initiate screening at age 50 or later and in those strategies that include annual screening rather than biennial screening. Annual screening 


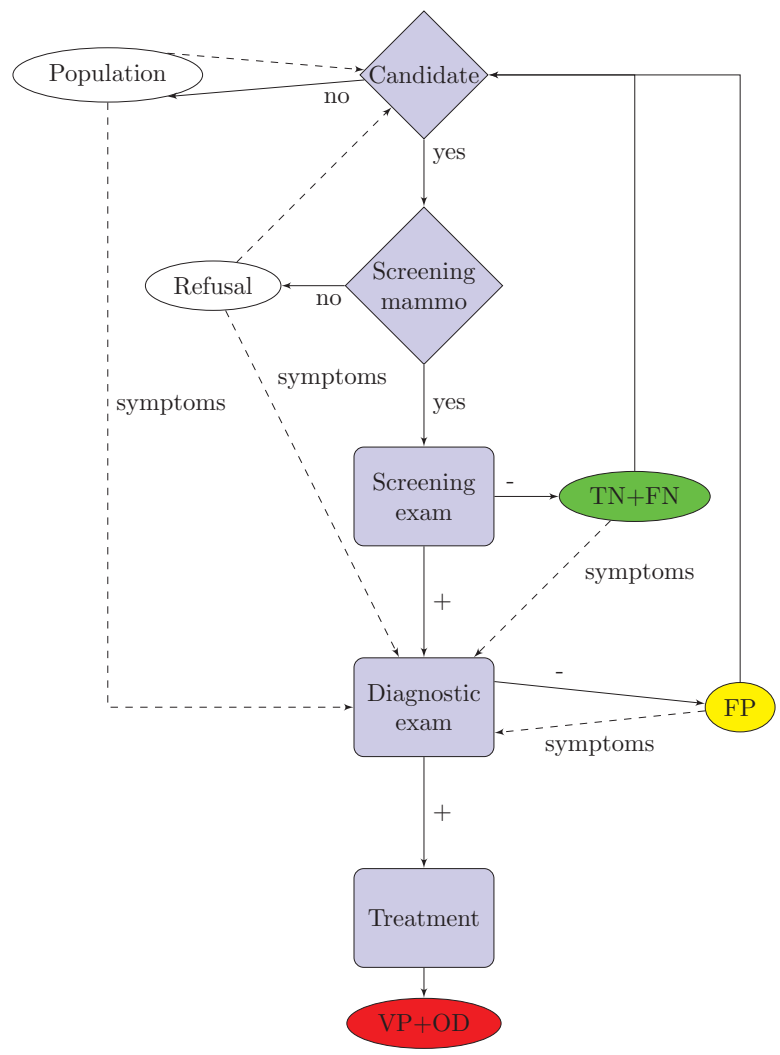

Fig. 1. Flow chart of a population screening program. ${ }^{2}$

yields almost twice as many FP results as biennial screening and many more women undergo unnecessary biopsies under annual screening than biennial screening.

An FP result can cause anxiety and discomfort in affected women. FP can increase adherence to a screening program (if there are concerns about changes, anxiety, etc.) or they can reduce the confidence of participants in the diagnostic test and, consequently, reduce their adherence to the program. Roman et al. (2011b) found that reattendance rate at the second screening was $79 \%$ for women with a FP result versus $85 \%$ for women

\footnotetext{
${ }^{2}$ In a given population, women within an age interval are offered a screening mammogram with certain periodicity. Each time a women is offered a mammography exam, she can accept or refuse it. Women who participate have a mammogram exam, which in case of a positive result leads to a diagnostic exam that may include additional non-invasive or invasive tests. In the case of a positive result, women are diagnosed and treated for BC. During this process, the group of women with negative screening exams consists of true negative cases (TN) and false negative cases (FN), while the group of women with positive screening exams and negative diagnostic exams defines the group of false positive cases (FP). If they are still candidates, these three groups of women together with the rest of population within program age range, will be offered a periodic new mammogram unless, before the next call to participate, they either develop an interval cancer and go straight to a diagnostic exam, or die. Women with a diagnosis of $\mathrm{BC}$ consist of true positive (TP) and overdiagnosed (OD) cases.
} 
without a FP result. These differences disappeared over time; in the seventh screening they were $95 \%$ versus $96 \%$. Risk factors for non-attendance to subsequent screenings were age, non-attendance to the first scheduled screening, and previous invasive procedures. Either a familial history of $\mathrm{BC}$ or the use of hormone replacement therapy were significant protective factors against non-attendance.

- False negative (FN) results. These occur when the mammogram result is negative even though BC is present. FN are a consequence of the lack of sensitivity of the mammography. A FN result can lead to a delay in cancer diagnosis due to a false sense of security, and in consequence to more aggressive treatment. High rates of FN indicate poor quality in the screening program.

- Interval cancers (IC). These are diagnosed in the interval between two screening exams. IC have a tumor growth rate higher than screen-detected tumors. IC are an important measure of screening effectiveness because they reflect screening sensitivity. A shorter time between exams could decrease the rates of IC, but would increase the risk of FP results and overdiagnosis. In Spain, Bare et al. (2008) found that 35\% of 57 interval cancers were true IC $(26 \%)$ or occult in the previous mammogram (9\%) and $14 \%$ were FN. The remaining $51 \%$ presented minimal signs in the previous mammogram $(18 \%)$ or were unclassifiable $(33 \%)$.

The incidence of interval cancer increases with age, breast density, hormone use, and family history (Lowery et al. (2011)). These women's characteristics could be used to develop risk profiles that may benefit from more intensive screening. In addition, Domingo et al. (2010) found that a more aggresive molecular phenotype, the triple negative, was more frequent in true interval cancers than in screen-detected cancers.

- Overdiagnosis and overtreatment $(O D)$. These occur when tumors that never would be diagnosed during an individual's life are diagnosed by screening. Overdiagnosis has a greater chance of occuring in older women, since other causes of death are competing with $\mathrm{BC}$ incidence. But they may also affect women of any age when tumors grow slowly or spontaneously regress (Zahl et al. (2008)).

Overdiagnosis affects the estimates of sensitivity, specificity, predictive values and incidence of cancer. Overdiagnosis estimates of BC are highly variable, as are the methods to estimate it. Jorgensen \& Gotzsche (2009), in a systematic review of BC incidence before and after the introduction of screening, estimated that one in three screen detected BCs is overdiagnosed. Our estimates of overdiagnosis in Catalonia ranged from $0.4 \%$ to $46.6 \%$ for women born around 1935 and 1950, respectively (Martinez-Alonso et al. (2010)).

\subsection{The lead-time and length biases of survival time}

Since screening mammography for early BC detection was introduced, assessing improvements in the survival from the time of diagnosis misrepresents the benefit because it is confounded by two biases specific to screening.

BC-specific survival is measured from the time of diagnosis to the time of death. If a BC is screen-detected before symptoms, then the lead time in diagnosis equals the length of time between screening detection and when the first signs/symptoms would have appeared. Even if early treatment had no benefit, the survival of screened individuals is longer simply by the addition of the lead time (Figure 2). The observed survival time $Z$ after the diagnosis by screening is defined as

$$
Z=X+Y,
$$



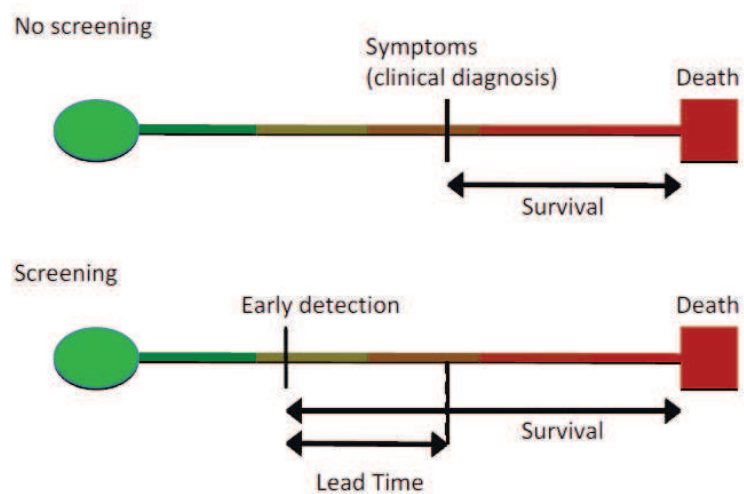

Fig. 2. Lead time bias. (Adapted from the National Cancer Institute)

- $Y$ : the lead-time.

- $X$ : the post-lead-time survival, the time from clinical detection to death or the end of study.

Length bias arises because the cancers detected in screening examinations are more likely to have slower growth than cases detected in the intervals between examinations and other groups of cancer cases not detected by screening. Patients with screen-detected cancers survive longer in part because the screened cancers are more indolent, but the improved survival cannot be accurately attributed to the early treatment (Figure 3). It is important to

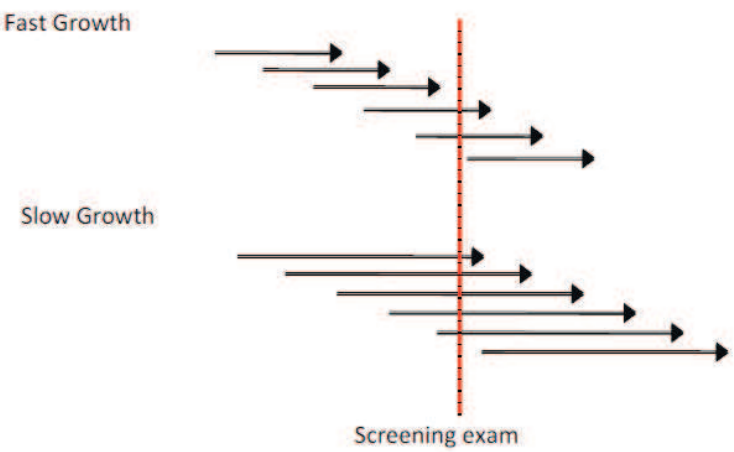

Fig. 3. Length bias.

take the lead-time and length biases into account when assessing the impact of screening. Different authors have developed methods to obtain non-biased survival time estimates Mahnken et al. (2008); Xu \& Prorok (1995); Zelen \& Feinleib (1969); Zelen \& Lee (2002). The mathematical models, developed by Lee \& Zelen (2008), that we use to assess the impact of early detection provide lead-time and lenght unbiased estimates.

\subsection{Economic evaluation}

Economic evaluation aims to provide health care decision makers with information on costs and outcomes of alternative interventions (Drummond et al. (1997)). To take economically 
efficient decisions one needs to compare costs and benefits of all technically efficient options. The basic tool is the cost-benefit analysis. Given the difficulty of assessing health in monetary terms, alternatively, in health economics, cost-effectiveness analysis is used. The result of the cost-effectiveness analysis is presented using a ratio between incremental costs and outcomes. The costs are measured in monetary units and the outcomes in years of life gained. However, the consideration that health outcomes are often multidimensional (e.g life expectancy and quality of life) has lead to the use of the QALYs in the denominator of the cost-effectiveness ratio. Then cost-effectiveness becomes a cost-utility analysis, and the values that are used to weigh life years gained in terms of quality reflect the preferences of individuals in relation to the different health states.

Oostenbrink et al. (2002) introduced a six-step procedure for estimating costs. These steps include 1) the perspective of the study; 2) the choice of cost categories; 3 ) the identification of units; 4) the measurement of resource use; 5) the monetary valuation of units; and 6) the calculation of unit costs. In addition, they mentioned several key issues regarding the standardisation of costs, e.g. methods for measurement and valuation or the reporting of outcomes.

Different types of costs must be included in the study based on the decision taken at Step 1. If the social perspective is taken, this involves estimating all the consequences of implementing a new intervention taking into account all the agents involved (thus it includes all costs and all benefits). However, many recent works have only the payer's perspective. If a study assesses both the social perspective and the payer's perspective, both results should be presented separately.

The choice of cost categories (Step 2) introduces the distinction between different cost items. In the literature there is no single classification of costs. Table 1 shows one of the most common classifications. Steps 3 to 6: identify the components of costs and measure the resources

\begin{tabular}{l|l}
\hline Direct health care costs & Costs directly related to prevention and treatment \\
\hline $\begin{array}{l}\text { Direct non health care } \\
\text { costs } 1,2\end{array}$ & Travel costs of patients and caregivers \\
Time costs of patients and caregivers \\
\hline Indirect health care costs & $\begin{array}{l}\text { Productivity losses, paid and unpaid, of caregivers and patients } \\
\text { caused by death or disability } \\
\text { Leisure time of patients and caregivers }\end{array}$ \\
\hline
\end{tabular}

Table 1. Example of cost categories. Classifications where most authors agree

${ }^{1}$ Weinstein (1990) includes in this section the costs of special education and juridical costs. Oostenbrink et al. (2002) included these items in indirect costs.

2 Oliva et al. (2004) include in this section the costs of paid caregivers.

used. Once the resources are identified, the unit values need to be estimated. This step is often difficult. Studies of economic efficiency attempt to examine real unitary costs for each resource. But these studies often use the charges as a proxy for cost. However, this equivalence is not recommended because costs and charges have a very different economic significance (Finkler (1982)) and it calls into question the cost analysis. Also, in this case, the "bottom-up" 
calculation, despite being the most appropriate, is more complex because it needs individual information on each item and it is nearly impossible to obtain all the data.

Despite economic evaluation studies being performed in a structured way, some issues remain controversial. One of the weaknesses of economic evaluation studies is the lack of systematic analysis of the costs which precludes a correct comparison of different studies. The two most important points of disagreement, among others, are the lack of consensus on how to take account of the indirect costs and the costs of the years of life gained.

A. Methods to estimate indirect costs

1. Human capital

The Human capital theory is based on the decisions of the individuals with respect to their investment preferences (Becker (1964)). Many individuals do not enter the labor market and continue studying, anticipating that in some years they will get higher revenues. In terms of health, it can be reasoned that individuals follow healthier lifestyles to increase their health. In both cases, in the future, individuals increase their productivity and contribute to economic growth.

The method of human capital presents some limitations. On the one hand, the calculation of indirect costs as the production loss due to mortality and morbidity is less than the social welfare loss. On the other hand, when individuals improve their health but do not return to the labor market the expenditure on health can not be considered an investment (e.g. retired individuals). However, as Sala-i-Martin (1992) and González-Páramo (1994) said, the contribution of these groups to social cohesion and positive externalities over the production makes it possible to consider the health expenditure as an investment

Puig-Junoy \& Pinto (2001), concluded that, in general, the human capital method may present strong inequities in the treatment given to individuals not included in the labor market, for various reasons. The method neither considers unpaid productivity losses (domestic productivity) nor the value of leisure time.

2. Frictional costs and the QALYs approach

These two methods are the principal alternatives to the human capital method. The frictional costs method considers the costs of replacing the sick worker to be indirect, and these costs are inversely related to unemployment. The QALY approach only includes temporal costs (travel and waiting time) and the additional costs of training a substitute in the work place as indirect costs (Oliva (1999)).

Lopez-Bastida et al. (2003) showed that indirect costs can represent between $20 \%$ (frictional cost method) and 70\% (human capital method) of the total cost of cancer. Antoñanzas et al. (2006) estimated the direct and indirect costs of cancer in Spanish regions for a five years follow-up, using the human hapital method. They did not include the costs of prevention or early detection. In Catalonia, direct costs of BC accounted for $53.7 \%$ of the total costs and indirect costs for $46.3 \%$.

B. Costs incurred as a result of years of life gained

The future costs may be due to treatments applied, new health problems or those that cause diseases not related, as well as other expenses of daily life. The key question is how to measure future costs. The definition of related diseases may be arbitrary and there is no consensus on the limits of what is understood by "other costs". 
Most papers include costs related to the disease throughout life. However, Meltzer (1997) stated that the clear theoretical implication from a model of lifetime utility maximization is that cost-effectiveness analyses should include all future costs, whether medical or nonmedical.

Meanwhile, Cutler (2007) introduced another element to the discussion when relating the introduction of an intervention to the health stock. Interventions that reduce disability could lower lifetime spending. If the intervention results in fewer lifetime years spent disabled, or if death occurs at a later age and the end-of-life care is cheaper, the total costs of care may decrease.

With regard to information provided to health policy makers by the cost-effectiveness analysis, it is important to note that the use of "lifetime costs" can influence the results substantially, particularly when the studied intervention adds years of life but not quality of life.

\section{Mathematical optimization}

According to Lee \& Zelen (1998), planning a screening program for early BC detection requires determining a) the individual characteristics that indicate when participation should start, b) the periodicity of the subsequent exams, and c) recommendations for high-risk individuals. An "optimal screening program" should take into account the benefits of screening, adverse effects and costs. More screenings at shorter intervals would make it possible to detect more tumors at initial stages, but part of this benefit would be counterbalanced by more false positive results, overdiagnosis and costs.

Mathematical optimization refers to the selection of a best element from some set of available alternatives. In early detection of BC, mathematical optimization can help finding the "best available" values of the objective function (for example number of QALYs) given a defined domain or set of inputs. Multiobjective optimization deals with having more than one objective -sometimes in conflict- in an optimization problem. For example, there is a screening strategy that produces the maximum number of QALYs, another that has the minimum cost -not necessarily the no screening strategy- and an infinite number of alternatives that are some combination of QALYs and costs.

\subsection{The One size fits all $\mathrm{BC}$ screening}

In 2009, the USPSTF (2009) updated the previous 2002 recommendation which supported screening mammography every 1-2 years for all women older than 40 years. The 2009 USPSTF guidelines recommended against routine screening of women aged 40-49 years and recommended biennial screening mammography for all women aged 50-74 year. Also, the USPSTF recommended against teaching breast self-examination and assessed as insufficient the evidence for clinical breast examination.

The USPSTF recommendations were based on the joint modeling work of Mandelblatt et al. (2009) for the CISNET, which provided estimates of the average benefits and harms expected across a cohort of contemporary women. The outcome meaures were the number of mammograms, reduction in deaths from BC or life-years gained, false-positive results, unnecessary biopsies, and overdiagnosis. The conclusion of the modeling analysis was that screening at biennial intervals is more efficient and provides a better balance of benefits and harms than screening at annual intervals. The USPSTF recommendations caused an intense 
discussion that lead to an update of their recommendation for women under 50 years of age. The new wording was: The decision to start regular, biennial screening mammography before the age of 50 years should be an individual one and take patient context into account, including the patient's values regarding specific benefits and harms.

In June 2011, the American College of Obstetricians and Gynecologists (ACOG) announced new BC screening guidelines, annual mammography screening beginning at age 40, that conflicts with the USPSTF recommendations (ACOG (2011)). The ACOG argument was the high incidence of BC in the US and the potential to reduce deaths from it when caught early.

It is important to note that neither the USPSTF nor the ACOG recommendations take into account the cost-effectiveness of the recommendations.

\subsection{The Risk based BC screening}

\subsubsection{Models that schedule exams based on BC risk}

Several authors have proposed the use of BC risk to guide screening recommendations.

\subsubsection{The risk-based threshold method}

Lee \& Zelen (1998) applied their modeling theory to scheduling the early detection exams. Every time a woman has a mammogram and the result is negative, the risk of BC decreases, and then starts to increase again as a function of age. Lee and Zelen introduced two basic ideas that either individually or together allow to obtain satisfactory examination schedules. The threshold method provides examination schedules so that the probability of an individual being in the preclinical state is always bounded by a preselected value. The concept of schedule sensitivity is the ratio of the expected number of $\mathrm{BC}$ cases diagnosed on scheduled examinations to the expected total number of $\mathrm{BC}$ cases. Combining the threshold and schedule sensitivity methods allows to compare different strategies and select the most appropriate. They started setting the probability of being in the preclinical state, $S_{p}$, at age 50 years as a threshold. When the woman's probability of being in $S_{p}$ reaches the threshold, it's time to have an exam. Since BC incidence increases with age, the intervals between the examinations become smaller as women get older.

\subsubsection{The Pareto-optimal criteria}

Rauner et al. (2010) designed a dynamic disease policy model for selecting Pareto-optimal screening strategies. They considered a rapidly progressing cancer in a high-risk group (younger women) and a more slowly progressing cancer in a low-risk group (older women). They applied the model to BC in Austria for a time horizon of 10 years. The problem of interest was to identify screening policies that maximize the total number of QALYs and minimize total costs, under selected budget constraints. The decision variables were optimized using the Pareto ant colony optimization (P-ACO) paradigm and used a discrete time population approach.

In the Rauner's model, the population is categorized as healthy, latently sick and identified sick individuals, with transition probabilities into the states and also to death. Effectiveness and costs are obtained with detailed equations in each category of individuals. The P-ACO algorithm is inspired by the search for food behavior of ant colonies. While walking, ants release pheromones on the ground making a path that other ants may follow. Shorter paths have a higher probability of being used as the scent of pheromones is stronger. This process 
can be simulated on the computer as an heuristic method to solve complex optimization problems. It generates solutions by successively adding a solution component (an ant move) to an initially empty set.

The Rauner's model showed that, in the case of low budgets, mammography screening should be exclusively directed to older women (aged 50-70 years) with infrequent, low screening for women younger than 50 years. The fact that cancer incidence is higher in older women dominates the effect of faster progressing cancers in younger women.

\subsubsection{Cost-effectiveness based on individual BC risk}

Schousboe et al. (2011) examined the health benefits and cost utility of mammography performed at different time intervals in women with different profiles of BC risk based on the Tice et al. (2008) model. According to the authors, the health benefits and cost utility of screening mammography may be strongly influenced by a woman's risk of BC, which can be estimated from her age, breast density on an initial mammogram, history of breast biopsy, and family history of BC. They used a Markov microsimulation model to compare the lifetime costs and health benefits of having mammography annually, biennially, or every 3 to 4 years or not having mammography. The data sources were the Surveillance, Epidemiology, and End Results program (SEER), Breast Cancer Surveillance Consortium (BCSC), and the medical literature. The time horizon was the lifetime and the authors assumed the perspective of the national health payer. Two cost-effectiveness thresholds were considered: $\$ 100,000$ or less and $\$ 50,000$ or less per QALY gained.

The results showed that the most cost-effective frequency of mammography depended on the studied risk factors. The authors presented a schema of recommendations about the frequency of mammography that differs from the more simplistic guidelines of 1 or 2 years starting at age 40 or 50 in the USA or biennially starting at 50 in many countries in Europe, regardless of risk factors. According to Schousboe et al. women may choose to have mammography at age 40 years, and those with average or low breast density and no other BC risk factors may start periodic screening at age 50 (with reassessment of breast density and the other risk factors). Or, women aged 50 to 79 years who have low breast density and no other BC risk factors, may consider having mammography less frequently than every two years. The authors concluded that mammography screening should be personalized on the basis of woman's risk factors and beliefs about the potential benefit and harms of screening.

Mandelblatt et al. (2011) mentioned several limitations of using the Schousboe et al. recommendations to guide personalised risk-based screening. Among others, difficulties in communicating to women and health providers or women that are left without guidance. Mandelblatt also warns about the efforts that need to be taken to understand the links between tumor types and risk factors and the mechanisms by which density is associated with BC.

\subsubsection{Models for predicting individual risk for breast cancer}

Population-based BC screening programs apply the same screening procedure to the entire target population. Currently, age is the only risk factor used to identify women who will be invited to participate. However, there are other risk factors like family history, genetic or breast density that have shown a significant association with BC risk. A key point to propose an "optimal screening program" is the individualized risk measurement. There are already several predictive models for individual risk assessment which incorporate both population 
risk and personal or family medical history, reproductive, endocrine or genetic factors. The incorporation of the risk measure in the organization of the screening program might allow the design of a screening protocol based on individual risk.

So far, the most known and used model for predicting the BC risk was developed by Gail et al. (1989). While previous models were aimed at specific populations such as relatives of $\mathrm{BC}$ affected women, the Gail model was the first that attempted to estimate the BC risk for women in the general population. The model was based on data from a case-control study conducted in women participating in a BC early detection program between 1973 and 1980.

The risk factors used in the model were age at menarche, age at first live birth, number of previous biopsies, and number of first degree relatives with BC. Individualized BC probabilities were obtained from information on relative risks, the baseline hazard rate and competing risks. The original Gail model, developed in the USA, included both invasive BC and DCIS. There is another model, exclusive of invasive BC and known as the Gail-2 model, that allows estimation of BC risk using an interactive web tool (Costantino et al. (1999)). In general, the Gail models showed good calibration. Ratios between expected and observed BC cases are above 0.80 in all evaluation studies and close to 1 for most of them (Cummings et al. (2009)). However, the ability to discriminate who will or will not have BC is poor, with values of the c-statistic ${ }^{3}$ ranging from 0.57 to 0.62 . Despite these results, the Gail-2 model is the most often used.

Since its publication, this model has undergone several changes with the inclusion or exclusion of different risk factors. It is also the model with the largest number of performance evaluations in women of different populations or races. Chen et al. (2006) modified the initial Gail model, including breast density as a risk factor. The Chen's model included age at first birth, number of previous biopsies, number of first-degree relatives with BC, breast density and weight. Compared to the initial Gail model, the Chen's model did not include age at menarche and some interaction terms of the Gail model.

Barlow et al. (2006) developed a model that incorporated breast density, hormone replacement therapy, body mass index, and the results of previous mammography exams as predictors of the risk of $\mathrm{BC}$ within one year of the screening mammogram. Race or ethnic group were also included in this model. With the addition of breast density as a risk factor it was expected that the Chen and the Barlow's models would improve discrimination. The c-statistic became 0.64 for the Chen's model and 0.63 and 0.62 for pre and post menopausal women, respectively, for the Barlow's model.

Tice et al. (2008) simplified the Barlow's model and extended it to assess the 5-year risk of BC. The Tice's model included age, race or ethnicity, family history of BC, history of breast biopsy and breast density. The model showed good calibration in major race and ethnic groups in the USA. But, as in the previous risk models, it had a modest ability to discriminate between women who will develop BC and those who will not (the c-statistic was 0.66 ). The authors concluded that the accuracy of the model needed to be further evaluated in independent populations before it could be recommended for clinical use.

\footnotetext{
${ }^{3}$ The c-statistic measures the ability of the model to separate women who will develop BC from those who will not. It estimates the proportion of pairs of women in which the woman with BC has a higher predicted risk than the woman without BC. A c-statistic of 0.5 is equivalent to no discrimination, and a c-statistic of 1.0 indicates perfect discrimination.
} 
The more recent models contain genetic characteristics. According to Pauw et al. (2009), the lifetime risk of developing $\mathrm{BC}$ in the general population is around $10 \%$. In contrast, the risk of $\mathrm{BC}$ at age 70 increases to $65 \%$ in women carrying the BRCA1 gene and up to $45 \%$ for carriers of the BRCA2 gene (Antoniou et al. (2003)). The Claus et al. (1991) models, BRCAPRO (Parmigiani et al. (1998)), BOADICEA (Antoniou et al. (2002)) and IBIS (Tyrer et al. (2004)), for example, incorporate the probability of carrying a mutation in these genes based on the individual's personal and family medical history of BC and ovarian cancer. The information needed to use these models makes their use difficult in clinical practice. Also, women with genetic $\mathrm{BC}$ risk have specific recomendations and screening protocols.

Individual risk estimated using risk models has been used in some cases to recommend screening to women aged 40-49 years, based on the estimated risk for 50 years old women without any risk factor (Gail \& Rimer (1998)). Since there is a wide variety of models, it is important to better analyze their applicability and effectiveness to specific populations or conditions, in order to select the most suitable. Besides, the application of statistical risk models for estimating individual risk is limited by the uncertainty of the estimates, in the case of a specific model, and the variability, in the case of different models.

One of the limitations of $\mathrm{BC}$ risk models is that the risk factors and their impact on risk of developing $\mathrm{BC}$ have been determined from observational studies in specific population. Therefore, the estimations obtained from these models may not be valid for other populations. We are currently assessing the predictions of the Gail's model, the Barlow's model and the Chen's model in Catalan population. Preliminary results show that these models are not well calibrated for the Catalan population.

\section{Our work}

\subsection{Cost-effectiveness of different screeening strategies in Catalonia. One size fits all BC screening}

Our objective was to help Catalan policy planners decide which population screening strategies were cost-effective while using limited public resources. We performed an economic evaluation of 20 screening strategies taking into account the cost over time of screening and subsequent medical costs, including diagnostic confirmation, initial treatment, follow-up and advanced care. Part of the cost-effectiveness analysis presented in this section has been published elsewhere (Carles et al. (2011)). Based on the literature, in the present work we have added an estimation of overall indirect costs to the direct costs that we used in our previous study.

We generated 20 possible screening strategies by varying the periodicity of screening exams and the age intervals of women screened. Annual or biennial screening with age intervals that started at 40, 45 and 50 years and ended at 69, 70, 74 and 79 years were combined. The background or non-screening scenario was also included. The probabilistic model developed by Lee \& Zelen (2008) was used to estimate the costs and effect of each screening scenario over time.

\subsubsection{The Lee and Zelen probabilistic model}

Lee and Zelen (LZ) developed a probabilistic model that predicts mortality as a function of the early detection strategy. The LZ model was one of the seven models used to estimate 
the impact of adjuvant therapy and mammography on US mortality from 1975 to 2000 (Cronin et al. (2006)). The LZ model had been previously validated by comparing the model predictions with the randomized breast cancer early detection trials. It is a flexible model that can accommodate complex natural histories and interventions (Lee \& Zelen (2006)).

The characteristics and assumptions of the LZ model are described in detail elsewhere (Lee \& Zelen (1998; 2003; 2008; 2006)). The assumptions of the LZ model are: (1) a four-state progressive disease in which a subject may be in a disease-free state $\left(S_{0}\right)$, preclinical disease state $\left(S_{p}\right.$ : capable of being diagnosed by a screening exam), clinical state $\left(S_{c}\right.$ : diagnosis by symptomatic detection), and death from BC state $\left(S_{d}\right) ;(2)$ age-dependent transitions into the different states; (3) age-dependent examination sensitivity; (4) age-dependent sojourn times in each state; and (5) exam-diagnosed cases have a stage-shift in the direction of more favorable prognosis relative to the distribution of stages in symptomatic detection.

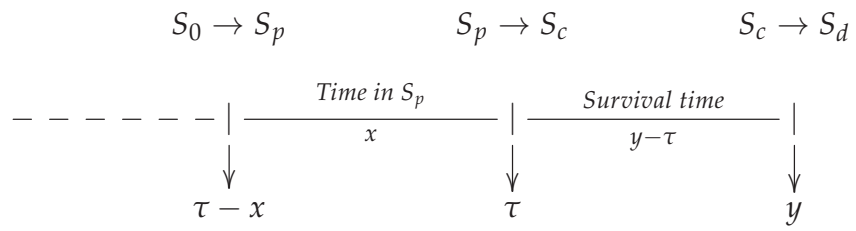

Where:

$\tau-x$ : Age entering $S_{p} ; \tau$ : Age of incidence (entering $S_{c}$ ); $y$ : Age at death.

The basic LZ model calculates the cumulative probability of death for a specific cohort exposed to any screening program after $T$ years of follow-up. Similarly, the cumulative probability of death for the cohort group without screening can be calculated. These probabilities were used to calculate the possible reduction in mortality from an early detection program after $T$ years of follow-up. We extended the model to estimate incidence and prevalence and also to perform an economic evaluation of different screening strategies. The inputs needed to model the Catalan data have been published elsewhere (Rue et al. (2008; 2009); Vilaprinyo et al. (2008; 2009)).

\subsubsection{Measuring the effect of different screening scenarios}

For each screening scenario and for the background, the effect of screening was measured with the number of QALYs. QALYs were estimated by applying the weights derived from the EuroQol EQ-5D utility scores that Stout et al. (2006) used in the USA. All the calculations assumed an initial population of 100,000 women at birth. The incidence of BC and mortality from other causes refer to the cohorts born in the period 1948-1952. The time horizon for the study was 40-79 years of age.

\subsubsection{Costs' considerations}

Direct and indirect healthcare costs were considered. The estimation of direct costs was partitioned into four parts: screening and diagnosis confirmation, initial treatment, follow-up and advanced care costs. Based on Antoñanzas et al. (2006), indirect costs were estimated as $46.3 \%$ of the total (direct+indirect) costs. All costs were valued in 2005 euros and both costs and outcomes were discounted at an annual rate of $3 \%$. 
The costs of screening mammograms, complementary tests and administrative expenses were obtained from the Early Detection Program of IMAS in the city of Barcelona. Data on treatment costs was obtained from a database that included 592 women consecutively diagnosed and initially treated for BC at the IMAS-Hospital del Mar in Barcelona in the period January 1st, 2000 - December 31, 2003. Details can be found in Carles et al. (2011).

\subsubsection{Cost-effectiveness analysis}

To compare the relative costs and outcomes of the different scenarios, we calculated the incremental cost-effectiveness ratio (ICER). The ICER indicates the additional cost of obtaining one additional unit of outcome when moving from one strategy to the next. Each scenario is compared with the next most efficient alternative. Once dominated or extended dominated strategies are excluded, the remaining strategies form the cost-effectiveness frontier, the efficient alternatives for which no other alternative policy exists that results in better effects for lower costs. When costs are plotted on the $Y$ axis and outcomes on the $X$ axis, a dominated strategy lies above and to the left of the non-dominated strategy.

Usually there is a social threshold, or willingness to pay, that constrains the choice between efficient strategies. But, finally, a rational decision maker has to decide whether or not to move up the efficiency frontier. Sacristan et al. (2002) and Pinto (2001) pointed to 30,000 €/ QALY as the threshold of reference for the public funding of health services in Spain. Ortún et al. (2004) indicated that this value is above the per capita income and above the average cost of a QALY in Spain in 2003. In any case, the most important fact is that health policy makers use this threshold as an initial value that can be modified to achieve equity and move towards a social welfare threshold.

Figure 4 presents the results of the cost-effectiveness analysis. The background scenario was taken as the reference scenario. All the screening alternatives represented increased effectiveness and costs with respect to the background scenario.

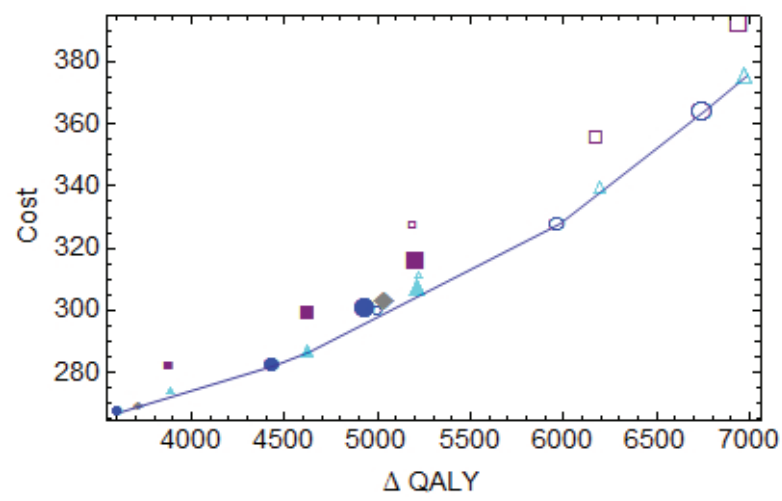

Fig. 4. Cost-effectiveness analysis of different screening strategies.

Figure 4 footnote: Cost per quality-adjusted life year (QALY). Empty figures correspond to annual strategies and full figures to biennial. Screening start age: 40 (big), 45 (medium) and 50 (small). Screening end age: 69 (circle), 70 (diamond), 74 (triangle), and 79 (square). The line joins the dominant scenarios. 
Table 2 shows the non-dominated or non-extended dominated alternatives. Six screening scenarios, three biennial and three annual, were selected: B50-69, B45-69, B45-74, A45-69, A40-69 and A40-74. Compared with the current public screening strategy, B50-69, all the remaining selected scenarios started the exams earlier and two of them ended later. Given the threshold accepted as willigness to pay, the three biennial alternatives could be considered for implementation.

\begin{tabular}{lccccc}
\hline Scenario & $\begin{array}{c}\text { Cost } \\
\left(\times 10^{6} €\right)\end{array}$ & $\begin{array}{c}\Delta \text { Cost } \\
\left(\times 10^{6} €\right)\end{array}$ & QALY $\triangle$ QALY $€ /$ QALY \\
\hline Background & 237.2 & 0 & & & \\
B 50-69 & 267.3 & 30.1 & 3,614 & 3,614 & 8,328 \\
B 45-69 & 282.3 & 15.0 & 4,447 & 833 & 18,061 \\
B 45-74 & 286.7 & 4.4 & 4,633 & 186 & 23,539 \\
A 45-69 & 327.9 & 41.2 & 5,979 & 1,346 & 30,578 \\
A 40-69 & 364.0 & 36.1 & 6,756 & 777 & 46,535 \\
A 40-74 & 375.5 & 11.5 & 6,987 & 231 & 49,786 \\
\hline
\end{tabular}

Table 2. Cost-effectiveness of mammography screening strategies in Catalonia (Spain). Incremental cost per QALY assuming a cohort of 100,000 women at birth. Dominated or extended-dominated strategies were not included.

\subsubsection{Comment}

A reduced number of screening strategies have been selected for consideration by researchers, decision makers and policy planners. Mathematical models are useful to assess the impact and costs of BC screening in a specific geographical area.

Variability in the methodologies, patient characteristics, perspectives and time horizons used by different authors is high. Some characteristics that are common to most of the studies are the acceptance of increasing costs of advanced cancer care over time and the substantial weight of hospitalization costs. A major challenge is to estimate the costs of advanced disease. Even though clinical practice guidelines provide standard treatment for advanced disease, very often treatments are customized according to the tumor or the patient's characteristics and the response to each treatment line.

Our previous work on cost-effectiveness (Carles et al. (2011) included an analysis of direct health costs based on a very detailed mathematical model. In the present work, indirect costs have been estimated according to the relation between total an indirect costs described by Antoñanzas et al. (2006), as was mentioned in the Costs'considerations section. The order of the non-dominated alternatives was the same using either direct or direct+indirect costs. But the inclusion of indirect costs changed the absolute value of the cost per QALY, allows a discussion based on the significance of the efficiency threshold used and changes the possibilities of implementing the efficient alternatives. In summary, the results of the economic evaluation provide information on the rank of efficient alternatives. The implementation of these alternatives depends on economic policy.

\subsection{A risk based scheduling of mammograms}

We compared the risk-based threshold method proposed by Lee \& Zelen (1998) with the personalized screening according to risk factors presented by Schousboe et al. (2011). As we 
mentioned earlier, the risk-based threshold method consists on having a mammogram every time that the probability of being in the pre-clinical state is an a priori fixed value. As Lee and Zelen did in their work, we chose as threshold the probability of being in the pre-clinical state at age 50. Schousboe et al. performed a cost-effectiveness analysis with two thresholds, $\$ 100,000$ or $\$ 50,000$ per QALY, to propose the risk individualized screening strategy.

We used the incidence model that Schousboe et al. (2011) estimated using the 1975-2005 SEER data. We used the relative risks of breast density, family history and previous biopsies, for the white US population, that Tice et al. (2008) determined. Figure 5 shows the incidence rates by age, according to the sixteen $\mathrm{BC}$ risk groups defined combining breast density (4 BI-RADS categories), family history (yes/no) and previous biopsies (yes/no). The bottom incidence curve refers to women with BI-RADS density 1 and neither family history nor previous biopsies whereas the top incidence curve corresponds to women with BI-RADS density 4 and both family history and previous biopsies.
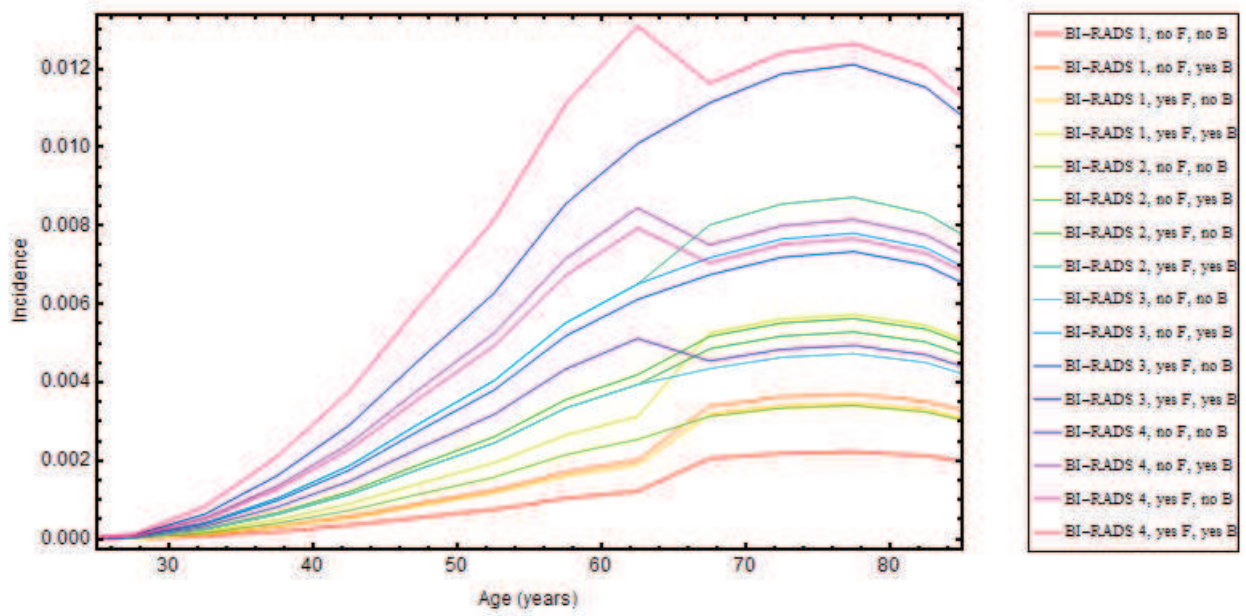

Fig. 5. Breast cancer incidence according to breast density, family history of BC and previous biopsies. F: family history, B: previous biopsies.

Given that different combinations of risk factors produce similar incidence functions, we decided to consider four BC risk groups, as an example. From low to very high risk:

1. Low : BI-RADS 1 with 0 or 1 risk factor, and BI-RADS 2 with 0 risk factors.

2. Intermediate: BI-RADS 1 with 2 risk factors, BI-RADS 2 with 1 risk factor, and BI-RADS 3-4 with 0 risk factors.

3. High: BI-RADS 2 with 2 risk factors, and BI-RADS 3-4 with 1 risk factor.

4. Very high: BI-RADS 3-4 with 2 risk factors

Figure 6 shows the probability of being in the pre-clinical state, $S_{p}$, in four different categories of women, each one of them belonging to one of the above defined risk groups. Figure 6 a) correspond to the low, b) to the intermediate, c) to the high and d) to the very high risk groups. Following Schousboe's recommendations, in all cases, there are mammograms at ages 40,50, 60 and 70 years. The horizontal dotted line indicates the risk of being in $S_{p}$ at 
age 50 in the general population, 0.00126 . On one hand, the intervals between exams become smaller as women get older. On the other hand, the number of exams increases as the risk of $\mathrm{BC}$ increases. The periodicity becomes approximately annual and every 6 months for women older than 60 years in categories c) and d), respectively.

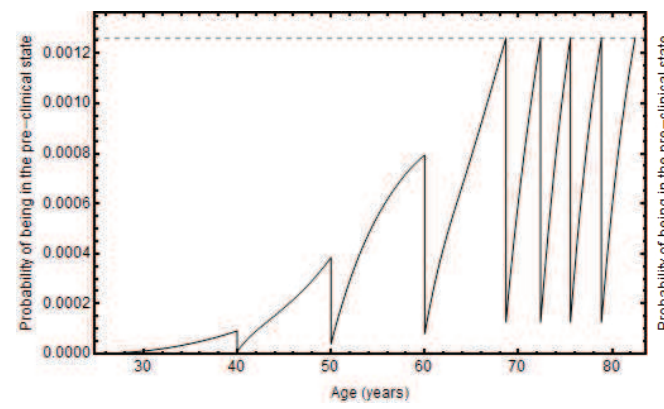

(a) BI-RADS 1 and 0 risk factors

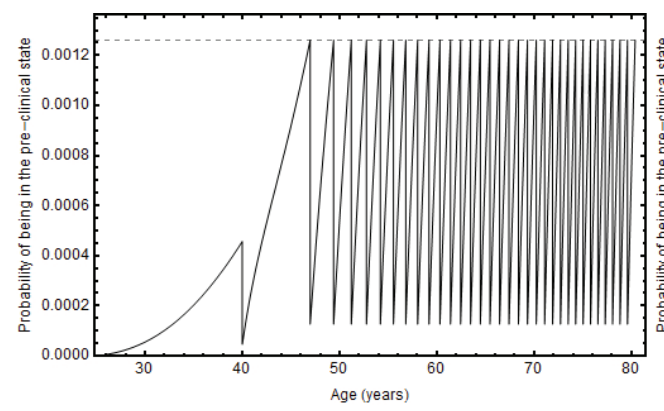

(c) BI-RADS 3 and 1 risk factors

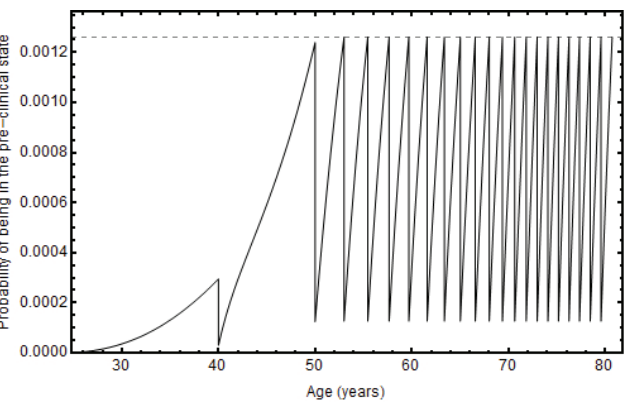

(b) BI-RADS 2 and 0 risk factors

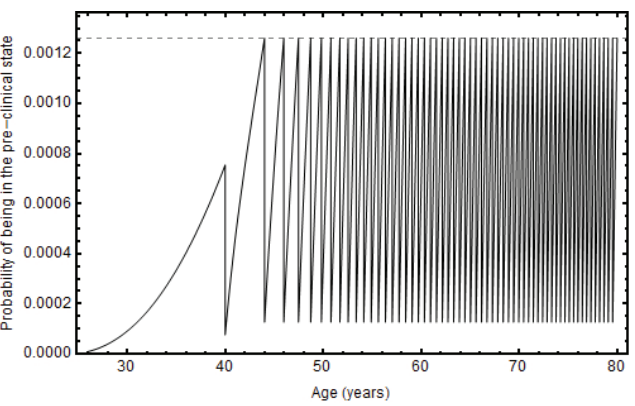

(d) BI-RADS 3 and 2 risk factors

Fig. 6. Examination schedule with age at initial examination $=40$ and reassessment at ages 50, 60 and 70. Examinations are scheduled whenever the probability of being in the preclinical state reaches the same value as at age 50. Adapted from Lee \& Zelen (1998).

Table 3 compares the screening recommendations based on the cost-effectiveness threshold and the BC risk-based threshod methods. For women in category a) both methods give a pattern of occasional mammograms. In category b) (intermediate risk) there is agreement for women aged 40-49 and a similar pattern for women 50-59. For women older than 60 years, the risk-based threshold method gives a higher number of exams. For women in categories c) and d) the risk-based method results in a higher number of exams, except for women 40-49 years in category c). It is important to note that the risk-based method would result in very high cost per QALY. The frequent exams in older women would cause low benefits in terms of QALY and high adverse effects (high rate of overdiagnosis) and therefore, these strategies would be dominated by less frequent strategies as Schousboe et al. proposed.

Figure 7 shows the probability of being in $S_{p}$ in the same four categories as Figure 6 . Here the exams correspond to the periodicity recommended by Schousboe. The dotted horizontal line indicates the threshold. Women in category a) would receive most of their mammograms 


\begin{tabular}{|c|c|c|c|}
\hline Age & $\$ 50,000$ per QALY & $\$ 100,000$ per QALY & \begin{tabular}{|c} 
BC risk based \\
threshold method \\
Exams at ages
\end{tabular} \\
\hline & \multicolumn{3}{|c|}{ a) BI-RADS 1 , no family history and no previous biopsies } \\
\hline $40-49$ & None until age 50 & None until age 50 & 40 \\
\hline $50-59$ & None until age 60 & Every 3-4 yr, Reassess at 60 & 50 \\
\hline $60-69$ & Every 3-4 yr, Reassess at 70 & Every 3-4 yr, Reassess at 70 & 60,68 \\
\hline \multirow[t]{2}{*}{$70-79$} & Every 3-4 yr & Every 3-4 yr & $72,75,79$ \\
\hline & \multicolumn{3}{|c|}{ b) BI-RADS 2, family history and no previous biopsies } \\
\hline $40-49$ & None un & til age 50 & 40 \\
\hline $50-59$ & Every 2 yr, $\mathrm{R}$ & Reassess at 60 & $50,53,56,58$ \\
\hline $60-69$ & Every 2 yr, $\mathrm{R}$ & Reassess at 70 & Every 1.5 yr \\
\hline \multirow[t]{2}{*}{$70-79$} & Ever & y 2 yr & Annually \\
\hline & \multicolumn{3}{|c|}{ c) BI-RADS 3, family history and no previous biopsies } \\
\hline $40-49$ & Every 2 yr, R & Reassess at 50 & $40,47,49$ \\
\hline $50-59$ & Every 2 yr, R & Reassess at 60 & Every 1.5 yr \\
\hline $60-69$ & Every 2 yr, $R$ & Reassess at 70 & Annually \\
\hline \multirow[t]{2}{*}{$70-79$} & Ever & y 2 yr & Annually \\
\hline & \multicolumn{3}{|c|}{ d) BI-RADS 3, family history and previous biopsies } \\
\hline $40-49$ & Every 2 yr, R & Reassess at 50 & $40,44,46,47.5,49$ \\
\hline $50-59$ & Every 2 yr, R & Reassess at 60 & Annually \\
\hline $60-69$ & Every 2 yr, R & Reassess at 70 & Every 6 months \\
\hline $70-79$ & Ever & y 2 yr & Every 6 months \\
\hline
\end{tabular}

Table 3. Screening recommendations and scheduling of exams.

at probabilities of being in $S_{p}$ lower than the threshold, indicating that they would be overscreened. Figures 7 b), c) and d) indicate that as BC risk increases, the periodicities recommended by Schousboe et al. result in an increased distance between the probability of being in $S_{p}$ and the threshold. In other words, in each exam the risk of BC is higher than in the previous exam. Considering that the benefit in terms of QALY decreases as women get older, as mentioned before, the more frequent strategies would become dominated by the less frequent.

The next step would be to perform an economic evaluation of One size fits all strategies and BC risk personalized strategies. A cost-effectiveness analysis, as the one we performed in section 4.1 , would provide valuable information to guide in the selection of an optimal strategy. 


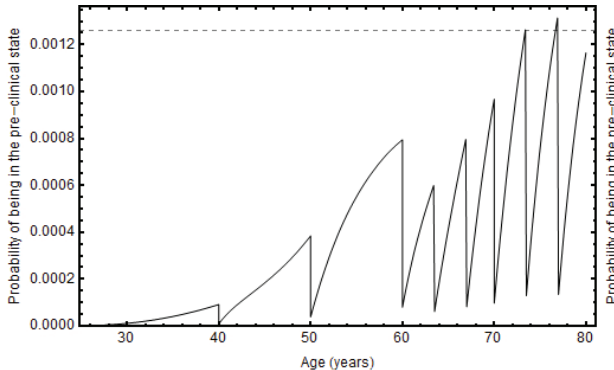

(a) BI-RADS 1 and 0 risk factors

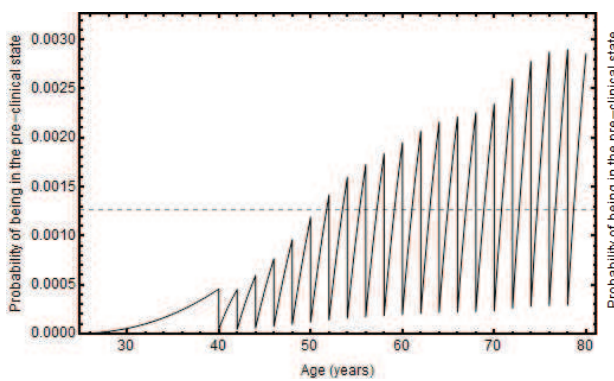

(c) BI-RADS 3 and 1 risk factors

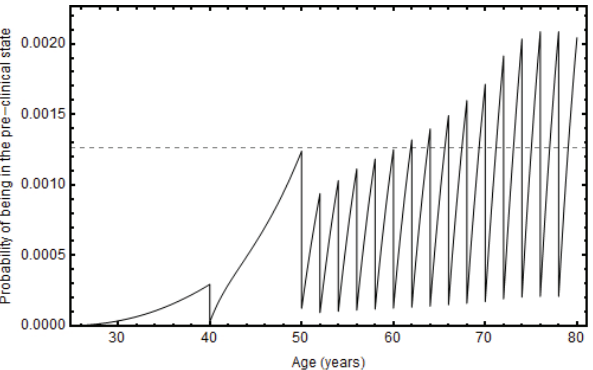

(b) BI-RADS 2 and 0 risk factors

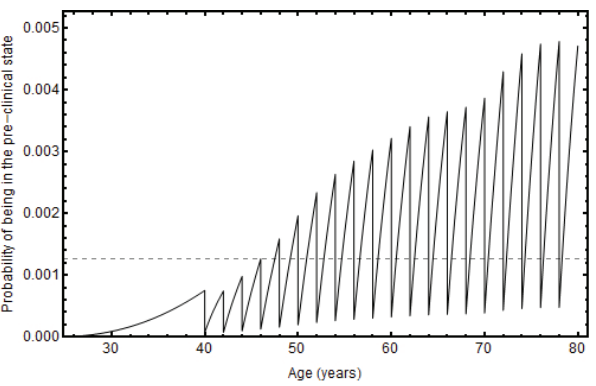

(d) BI-RADS 3 and 2 risk factors

Fig. 7. Examination schedule with age at initial examination $=40$ and reassessment at ages 50, 60 and 70. Examinations are scheduled according the Schousboe et al. (2011) recommendations. The horizontal dotted line corresponds to the probability of being in $S_{p}$ at age 50 .

\section{Conclusions and future research}

$\mathrm{BC}$ screening has brought benefits, but the costs have not been low. We are beginning to have information on the undesirable effects of population screening programs. Overdiagnosis, overtreatment, anxiety and unnecessary tests need to be addressed adequately. Is there enough evidence to justify changing to a new, evidence-based system? It seems clear that the current One size fits all paradigm is inadequate in light of current BC research. Screening with fixed periodicity results in some women being screened too much and others not being screened often enough. Using what we know now about the natural history of BC and the characteristics of current screening technologies, it is possible to develop better systems that are more cost-effective and better tailored to the patient's needs.

Change is always difficult in health care provision systems. The process of spreading knowledge has its own rules and requires time and leaders who believe in change. Many examples show that the gap between evidence and its use in clinical practice is enormous, despite the high cost and harmful consequences of not using evidence. Professionals working in the field of screening may be resistant to new methods, but the current long-term economic crisis makes it necessary to review health care interventions to ensure that they are maximizing their return on scarce resources, especially those interventions designed to prevent or to detect diseases early. 
The theoretical advantages of a new approach require a careful, practical evaluation of how to put it into effect. How would such a change be initiated and managed? According to Berwick $(2005 ; 2003)$ the translation of a new technology into improved patient outcomes involves at least three overlapping processes: (1) decisions by a healthcare delivery organizations to adopt these new technologies that are based on assessment of the efficacy and cost-effectiveness of the technologies, (2) implementing these technologies within the complex organizational structure of healthcare providers, and (3) monitoring the use of these new technologies.

What areas are the highest priority for ongoing research? There are some suggestions below:

1. Improvement of tools to measure BC risk. Dynamic evaluations are important, to the extent that relevant information becomes available to incorporate into an individual risk profile. Changes in breast density, family history, exposure to hormone replacement and previous biopsies are examples of characteristics that should be considered to re-adjust previous measurements of BC risk.

2. Conduct pilot studies of individualized screening. Assess benefits, adverse effects, costs and difficulties in implementing them.

3. Investigate biological markers that help predict BC risk and risk of in situ tumors becoming invasive.

4. Investigate indolent disease markers. Apply watchful waiting protocols instead of aggressive interventions (mastectomies, chemotherapy).

5. Communicate facts (benefits and harms) about BC screening to women more effectively.

6. Improve information systems used to assess the effectiveness of interventions and opportunities to make improvements. This calls for shared databases that integrate basic, clinical and epidemiological research.

New technologies or interventions can certainly increase both life expectancy and quality of life. However, the benefits may not exceed the costs when costs are considered in the broadest sense: direct, indirect and intangible. Thus, as stated by Ortún et al. (2004), the overuse, underuse and poor use exist in any health system and this negatively impacts the health of the population. Understanding and analyzing effectiveness, beyond efficacy, is essential to optimize the allocation of scarce resources and maximize the objective function that includes both life expectancy and quality of life.

\section{References}

Abellán, J. M., Sánchez, F. I. \& Martínez, J. E. (2008). Economic assessment of health care technologies. are they worth the cost?, Cuadernos Económicos de ICE 75: 189-208.

ACOG, American College of Obstetricians and Gynecologists (2011). Practice bulletin no. 122: Breast cancer screening, Obstet Gynecol 118: 372-382.

Antoñanzas, F., Oliva, J., Velasco, M., Zozaya, N., Lorente, R. \& López-Bastida, J. (2006). Direct and indirect costs of cancer in Spain, Cuadernos Económicos de ICE pp. 281-309.

Antoniou, A. C., Pharoah, P. D., McMullan, G., Day, N. E., Stratton, M. R., Peto, J., Ponder, B. J. \& Easton, D. F. (2002). A comprehensive model for familial breast cancer incorporating BRCA1, BRCA2 and other genes, Br J Cancer 86: 76-83.

Antoniou, A., Pharoah, P. D., Narod, S., Risch, H. A., Eyfjord, J. E., Hopper, J. L., Loman, N., Olsson, H., Johannsson, O., Borg, A., Pasini, B., Radice, P., Manoukian, S., Eccles, D. M., Tang, N., Olah, E., Anton-Culver, H., Warner, E., Lubinski, J., Gronwald, J., 
Gorski, B., Tulinius, H., Thorlacius, S., Eerola, H., Nevanlinna, H., Syrjakoski, K., Kallioniemi, O. P., Thompson, D., Evans, C., Peto, J., Lalloo, F., Evans, D. G. \& Easton, D. F. (2003). Average risks of breast and ovarian cancer associated with BRCA1 or BRCA2 mutations detected in case Series unselected for family history: a combined analysis of 22 studies, Am J Hum Genet 72: 1117-1130.

Autier, P., Boniol, M., Gavin, A. \& Vatten, L. J. (2011). Breast cancer mortality in neighbouring European countries with different levels of screening but similar access to treatment: trend analysis of WHO mortality database, BMJ 343: d4411.

Bare, M., Sentis, M., Galceran, J., Ameijide, A., Andreu, X., Ganau, S., Tortajada, L., Planas, J. \& of Sabadell Cerdanyola Research Group on Interval Cancers, B. C. S. P. B. (2008). Interval breast cancers in a community screening programme: frequency, radiological classification and prognostic factors, Eur J Cancer Prev 17: 414-421.

Barlow, W. E., White, E., Ballard-Barbash, R., Vacek, P. M., Titus-Ernstoff, L., Carney, P. A., Tice, J. A., Buist, D. S., Geller, B. M., Rosenberg, R., Yankaskas, B. C. \& Kerlikowske, K. (2006). Prospective breast cancer risk prediction model for women undergoing screening mammography, J Natl Cancer Inst 98: 1204-1214.

Becker, G. S. (1964). Human capital, Columbia University Press, New York.

Berry, D. A., Cronin, K. A., Plevritis, S. K., Fryback, D. G., Clarke, L., Zelen, M., Mandelblatt, J. S., Yakovlev, A. Y., Habbema, J. D., Feuer, E. J., Intervention, C. \& Collaborators, S. M. N. C. (2005). Effect of screening and adjuvant therapy on mortality from breast cancer, N Engl J Med 353: 1784-1792.

Berwick, D. (2005). Translating new technologies into improved patient outcomes, Saving women's lives. Strategies for improving breast cancer detection and diagnosis, National Academies Press (US), Washington (DC).

Berwick, D. M. (2003). Disseminating innovations in health care, JAMA 289: 1969-1975.

Black, W. C. (2000). Overdiagnosis: An underrecognized cause of confusion and harm in cancer screening, J Natl Cancer Inst 92: 1280-1282.

Carles, M., Vilaprinyo, E., Cots, F., Gregori, A., Pla, R., Roman, R., Sala, M., Macia, F., Castells, X. \& Rue, M. (2011). Cost-effectiveness of early detection of breast cancer in Catalonia (Spain), BMC Cancer 11: 192.

Chen, J., Pee, D., Ayyagari, R., Graubard, B., Schairer, C., Byrne, C., Benichou, J. \& Gail, M. H. (2006). Projecting absolute invasive breast cancer risk in white women with a model that includes mammographic density, J Natl Cancer Inst 98: 1215-1226.

Claus, E. B., Risch, N. \& Thompson, W. D. (1991). Genetic analysis of breast cancer in the cancer and steroid hormone study, Am J Hum Genet 48: 232-242.

Costantino, J. P., Gail, M. H., Pee, D., Anderson, S., Redmond, C. K., Benichou, J. \& Wieand, H. S. (1999). Validation studies for models projecting the risk of invasive and total breast cancer incidence, J Natl Cancer Inst 91: 1541-1548.

Cronin, K. A., Feuer, E. J., Clarke, L. D. \& Plevritis, S. K. (2006). Impact of adjuvant therapy and mammography on U.S. mortality from 1975 to 2000: comparison of mortality results from the CISNET breast cancer base case analysis, J Natl Cancer Inst Monogr (36): 112-121.

Cummings, S. R., Tice, J. A., Bauer, S., Browner, W. S., Cuzick, J., Ziv, E., Vogel, V., Shepherd, J., Vachon, C., Smith-Bindman, R. \& Kerlikowske, K. (2009). Prevention of breast cancer in postmenopausal women: approaches to estimating and reducing risk, J Natl Cancer Inst 101: 384-398. 
Cutler, D. M. (2007). The lifetime costs and benefits of medical technology, Technical Report 13478, NBER Working Papers, National Bureau of Economic Research, Inc.

Domingo, L., Sala, M., Servitja, S., Corominas, J. M., Ferrer, F., Martinez, J., Macia, F., Quintana, M. J., Albanell, J. \& Castells, X. (2010). Phenotypic characterization and risk factors for interval breast cancers in a population-based breast cancer screening program in Barcelona, Spain, Cancer Causes Control 21: 1155-1164.

Drummond, M. F., O'Brien, B. J., Stoddart, G. L. \& Torrance, G. W. (1997). Methods for the Evaluation of Health Care Programmes (2nd Edition), Oxford University Press, Oxford.

Duffy, S. W., Tabar, L., Olsen, A. H., Vitak, B., Allgood, P. C., Chen, T. H., Yen, A. M. \& Smith, R. A. (2010). Absolute numbers of lives saved and overdiagnosis in breast cancer screening, from a randomized trial and from the Breast Screening Programme in England, J Med Screen 17: 25-30.

Ferlay, J., Autier, P., Boniol, M., Heanue, M., Colombet, M. \& Boyle, P. (2007). Estimates of the cancer incidence and mortality in Europe in 2006, Ann Oncol 18: 581-592.

Feuer, E. J. (2006). Modeling the impact of adjuvant therapy and screening mammography on U.S. breast cancer mortality between 1975 and 2000: introduction to the problem, $J$ Natl Cancer Inst Monogr (36): 2-6.

Finkler, S. A. (1982). The distinction between cost and charges, Ann Intern Med 96: 102-109.

Gail, M. H., Brinton, L. A., Byar, D. P., Corle, D. K., Green, S. B., Schairer, C. \& Mulvihill, J. J. (1989). Projecting individualized probabilities of developing breast cancer for white females who are being examined annually, J Natl Cancer Inst 81: 1879-1886.

Gail, M. \& Rimer, B. (1998). Risk-based recommendations for mammographic screening for women in their forties, J Clin Oncol 16: 3105-3114.

González-Páramo, J. M. (1994). EI sector público español: una aproximación a la panorámica actual. In: Gasto social y crecimiento económico en el estado de bienestar. Hacienda Pública Española Monografía n. 2, Instituto de Estudios Fiscales, Madrid.

Gotzsche, P. C., Hartling, O. J., Nielsen, M., Brodersen, J. \& Jorgensen, K. J. (2009). Breast screening: the facts-or maybe not, BMJ 338: b86.

Jorgensen, K. J. \& Gotzsche, P. C. (2009). Overdiagnosis in publicly organised mammography screening programmes: systematic review of incidence trends, BMJ 339: b2587.

Jorgensen, K. J., Klahn, A. \& Gotzsche, P. C. (2007). Are benefits and harms in mammography screening given equal attention in scientific articles? A cross-sectional study, BMC Med 5: 12.

Lee, S. J. \& Zelen, M. (1998). Scheduling periodic examinations for the early detection of disease: Applications to breast cancer, Journal of the American Statistical Association 93: 1271-1281.

Lee, S. J. \& Zelen, M. (2003). Modelling the early detection of breast cancer, Ann Oncol 14: 1199-1202.

Lee, S. J. \& Zelen, M. (2008). Mortality modeling of early detection programs, Biometrics 64: 386-395.

Lee, S. \& Zelen, M. (2006). A stochastic model for predicting the mortality of breast cancer, $J$ Natl Cancer Inst Monogr pp. 79-86.

Lopez-Bastida, J., Serrano-Aguilar, P. \& Duque-Gonzalez, B. (2003). Socioeconomic costs of cardiovascular disease and cancer in the Canary Islands (Spain) in 1998, Gac Sanit 17: 210-217. 
Lowery, J. T., Byers, T., Hokanson, J. E., Kittelson, J., Lewin, J., Risendal, B., Singh, M. \& Mouchawar, J. (2011). Complementary approaches to assessing risk factors for interval breast cancer, Cancer Causes Control 22: 23-31.

Mahnken, J. D., Chan, W., Freeman, D. H., J. \& Freeman, J. L. (2008). Reducing the effects of lead-time bias, length bias and over-detection in evaluating screening mammography: a censored bivariate data approach, Stat Methods Med Res 17: 643-663.

Mandelblatt, J. S., Cronin, K. A., Bailey, S., Berry, D. A., de Koning, H. J., Draisma, G., Huang, H., Lee, S. J., Munsell, M., Plevritis, S. K., Ravdin, P., Schechter, C. B., Sigal, B., Stoto, M. A., Stout, N. K., van Ravesteyn, N. T., Venier, J., Zelen, M., Feuer, E. J., of the Cancer Intervention, B. C. W. G. \& Network, S. M. (2009). Effects of mammography screening under different screening schedules: model estimates of potential benefits and harms, Ann Intern Med 151: 738-747.

Mandelblatt, J. S., Stout, N. \& Trentham-Dietz, A. (2011). To screen or not to screen women in their 40s for breast cancer: is personalized risk-based screening the answer?, Ann Intern Med 155: 58-60.

Martinez-Alonso, M., Vilaprinyo, E., Marcos-Gragera, R. \& Rue, M. (2010). Breast cancer incidence and overdiagnosis in Catalonia (Spain), Breast Cancer Res 12: R58.

Meltzer, D. (1997). Accounting for future costs in medical cost-effectiveness analysis, J Health Econ 16: 33-64.

Oliva, J. (1999). La valoración de los costes indirectos en economía de la salud, Technical Report 9917, Universidad Complutense de Madrid.

Oliva, J., Lobo, F., López-Bastida, J., Duque, B. \& Osuna, R. (2004). Costes no sanitarios ocasionados por las enfermedades isquémicas del corazón en España, Cuadernos Económicos de ICE pp. 263-298.

Oostenbrink, J. B., Koopmanschap, M. A. \& Rutten, F. F. (2002). Standardisation of costs: the dutch manual for costing in economic evaluations, Pharmacoeconomics 20: 443-454.

Ortún, V., Meneu, R. \& Peiró, S. (2004). El impacto de los servicios sanitarios sobre la salud, Más recursos para la salud?, Masson-Salvat, Barcelona.

Parmigiani, G., Berry, D. \& Aguilar, O. (1998). Determining carrier probabilities for breast cancer-susceptibility genes BRCA1 and BRCA2, Am J Hum Genet 62: 145-158.

Pauw, A. D., Stoppa-Lyonnet, D., Andrieu, N. \& Asselain, B. (2009). Estimation of individual breast cancer risk: relevance and limits of risk estimation models, Bull Cancer 96: 979-988.

Pinto, J. L. (2001). Cuánto vale la pena gastarse para ganar un año de vida ajustado por calidad? Un estudio empírico, El valor monetario de la salud, Springer-Verlag, Barcelona.

Puig-Junoy, J. \& Pinto, J. L. (2001). El coste de oportunidad del tiempo remunerado en la producción de salud, Technical Report 39, CRES-Universitat Pompeu Fabra.

Rauner, M., Gutjahr, W. J., Heidenberger, K., Wagner, J. \& Paisa, J. (2010). Dynamic policy modeling for chronic diseases: metaheuristic-based identification of Pareto-optimal screening strategies, Operations Research 58: 1269-1286.

Roman, R., Sala, M., De La Vega, M., Natal, C., Galceran, J., Gonzalez-Roman, I., Baroja, A., Zubizarreta, R., Ascunce, N., Salas, D. \& Castells, X. (2011b). Effect of false-positives and women's characteristics on long-term adherence to breast cancer screening, Breast Cancer Res Treat .

Roman, R., Sala, M., Salas, D., Ascunce, N., Zubizarreta, R., Castells, X. \& Cumulative False Positive Risk Group. (2011a). Effect of protocol-related variables and women's 
characteristics on the cumulative false-positive risk in breast cancer screening, Ann Oncol .

Rue, M., Carles, M., Vilaprinyo, E., Martinez-Alonso, M., Espinas, J. A., Pla, R. \& Brugulat, P. (2008). Dissemination of periodic mammography and patterns of use, by birth cohort, in Catalonia (Spain), BMC Cancer 8: 336.

Rue, M., Vilaprinyo, E., Lee, S., Martinez-Alonso, M., Carles, M., Marcos-Gragera, R., Pla, R. \& Espinas, J. A. (2009). Effectiveness of early detection on breast cancer mortality reduction in Catalonia (Spain), BMC Cancer 9: 326.

Sacristan, J. A., Oliva, J., Del Llano, J., Prieto, L. \& Pinto, J. L. (2002). What is an efficient health technology in Spain?, Gac Sanit 16: 334-343.

Sala-i-Martin, X. (1992). Transfers, Technical Report 4186, NBER Working Papers, National Bureau of Economic Research, Inc.

Schousboe, J. T., Kerlikowske, K., Loh, A. \& Cummings, S. R. (2011). Personalizing mammography by breast density and other risk factors for breast cancer: analysis of health benefits and cost-effectiveness, Ann Intern Med 155: 10-20.

Stout, N. K., Rosenberg, M. A., Trentham-Dietz, A., Smith, M. A., Robinson, S. M. \& Fryback, D. G. (2006). Retrospective cost-effectiveness analysis of screening mammography, J Natl Cancer Inst 98: 774-782.

Tabar, L., Yen, M. F., Vitak, B., Chen, H. H., Smith, R. A. \& Duffy, S. W. (2003). Mammography service screening and mortality in breast cancer patients: 20-year follow-up before and after introduction of screening, Lancet 361: 1405-1410.

Tice, J. A., Cummings, S. R., Smith-Bindman, R., Ichikawa, L., Barlow, W. E. \& Kerlikowske, K. (2008). Using clinical factors and mammographic breast density to estimate breast cancer risk: development and validation of a new predictive model, Ann Intern Med 148: 337-347.

Tyrer, J., Duffy, S. W. \& Cuzick, J. (2004). A breast cancer prediction model incorporating familial and personal risk factors, Stat Med 23: 1111-1130.

USPSTF (2009). Screening for breast cancer: U.S. Preventive Services Task Force recommendation statement, Ann Intern Med 151: 716-26, W-236.

Vilaprinyo, E., Gispert, R., Martinez-Alonso, M., Carles, M., Pla, R., Espinas, J. A. \& Rue, M. (2008). Competing risks to breast cancer mortality in Catalonia, BMC Cancer 8: 331.

Vilaprinyo, E., Rue, M., Marcos-Gragera, R. \& Martinez-Alonso, M. (2009). Estimation of age- and stage-specific Catalan breast cancer survival functions using US and Catalan survival data, BMC Cancer 9: 98.

Weinstein, M. C. (1990). Principles of cost-effective resource allocation in health care organizations, Int J Technol Assess Health Care 6: 93-103.

Xu, J. L. \& Prorok, P. C. (1995). Non-parametric estimation of the post-lead-time survival distribution of screen-detected cancer cases, Stat Med 14: 2715-2725.

Zahl, P. H., Maehlen, J. \& Welch, H. G. (2008). The natural history of invasive breast cancers detected by screening mammography, Arch Intern Med 168: 2311-6.

Zelen, M. \& Feinleib, M. (1969). On the theory of screening for chronic diseases, Biometrika 56: 601-614.

Zelen, M. \& Lee, S. J. (2002). Models and the early detection of disease: methodological considerations, Cancer Treat Res 113: 1-18. 


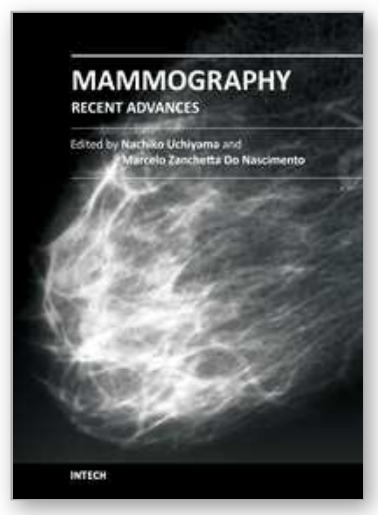

\author{
Mammography - Recent Advances \\ Edited by Dr. Nachiko Uchiyama
}

ISBN 978-953-51-0285-4

Hard cover, 418 pages

Publisher InTech

Published online 16, March, 2012

Published in print edition March, 2012

In this volume, the topics are constructed from a variety of contents: the bases of mammography systems, optimization of screening mammography with reference to evidence-based research, new technologies of image acquisition and its surrounding systems, and case reports with reference to up-to-date multimodality images of breast cancer. Mammography has been lagged in the transition to digital imaging systems because of the necessity of high resolution for diagnosis. However, in the past ten years, technical improvement has resolved the difficulties and boosted new diagnostic systems. We hope that the reader will learn the essentials of mammography and will be forward-looking for the new technologies. We want to express our sincere gratitude and appreciation?to all the co-authors who have contributed their work to this volume.

\title{
How to reference
}

In order to correctly reference this scholarly work, feel free to copy and paste the following:

Montserrat Rue, Misericordia Carles, Ester Vilaprinyo, Roger Pla, Montserrat Martinez-Alonso, Carles Forne, Albert Roso and Arantzazu Arrospide (2012). How to Optimize Population Screening Programs for Breast Cancer Using Mathematical Models, Mammography - Recent Advances, Dr. Nachiko Uchiyama (Ed.), ISBN: 978-953-51-0285-4, InTech, Available from: http://www.intechopen.com/books/mammography-recentadvances/how-to-optimize-population-screening-programs-for-breast-cancer-using-mathematical-models

\section{INTECH}

open science | open minds

\author{
InTech Europe \\ University Campus STeP Ri \\ Slavka Krautzeka 83/A \\ 51000 Rijeka, Croatia \\ Phone: +385 (51) 770447 \\ Fax: +385 (51) 686166 \\ www.intechopen.com
}

\author{
InTech China \\ Unit 405, Office Block, Hotel Equatorial Shanghai \\ No.65, Yan An Road (West), Shanghai, 200040, China \\ 中国上海市延安西路65号上海国际贵都大饭店办公楼 405 单元 \\ Phone: +86-21-62489820 \\ Fax: +86-21-62489821
}


(C) 2012 The Author(s). Licensee IntechOpen. This is an open access article distributed under the terms of the Creative Commons Attribution 3.0 License, which permits unrestricted use, distribution, and reproduction in any medium, provided the original work is properly cited. 